\title{
An explicit method of mesoscale convective storm prediction for the central region of Russia
}

\author{
Inna M. Gubenko ${ }^{1,2}$, Maria M. Kurbatova ${ }^{1,2}$, and Konstantin G. Rubinstein ${ }^{1,2}$ \\ ${ }^{1}$ Department of Long-term Weather Forecasting, Hydrometeorological Research Center of Russia, \\ Moscow, 123242, Russia \\ ${ }^{2}$ Department of Applied Mathematical Modelling, Nuclear Safety Institute of RAS, \\ Moscow, 115191, Russia \\ Correspondence: Inna M. Gubenko (img0504@yandex.ru)
}

Received: 11 February 2018 - Revised: 24 July 2018 - Accepted: 7 August 2018 - Published: 27 August 2018

\begin{abstract}
This work presents simulation results of the storm observed on the 13-14 July 2016 over the Central region of Russia. The Cumulonimbus cloud $(\mathrm{Cb})$ electrification model coupled with the numerical weather prediction model WRF-ARW were used for this study. The prognostic values of the electric field magnitude were compared with observations. Forecast scores were obtained. The results show that the proposed approach of explicit modelling of the electric field is applicable to short-term forecasting of intense convection and passage tracking of storms. Obtaining varying values of the electric field could help to identify the diversity of hazardous weather phenomena associated with convection.
\end{abstract}

\section{Introduction}

The main threat to society, industry and the environment is an increase in the frequency and magnitude of extreme weather. These phenomena include hazardous convective weather events - intense thunderstorms, heavy rain, squalls and hail. All these weather events are associated with the formation of mesoscale convective systems (MCSs). However, the specific mechanisms affecting the formation and evolution of convective clouds have been insufficiently studied. One of these mechanisms is the atmospheric electrical process, which makes a significant contribution to the initiation of severe weather. Since there is a lack of observation of the electrical parameters in thunderclouds, an alternative tool for this analysis could be the electrification model. The proposed technique is based on an explicit calculation of the generation and separation of the electric charges in convective clouds. Better understanding of atmospheric electrical processes could improve the severe weather forecast characterized by a small spatio-temporal scale. The main objective of this study is the short-term forecast of the storm observed 13-14 July 2016 over central Russia. It also includes an analysis of the electric field intensity threshold for lightning initiation. The $\mathrm{Cb}$ model coupled with the numerical weather prediction model WRF-ARW (Wang et al., 2012) are used for this research.

\section{Methodology}

\subsection{Case study of the convective event: background}

The analysed MCS began to form over Belarus and the Smolensk region of Russia at 15:00 UTC 13 July 2016. Passage of the storm over the Moscow region began at 18:30 UTC. It moved from the northwest to the east until 22:00 UTC. The convective area accompanied by severe thunderstorm activity anomalies, hail and intense cumulous precipitation was observed. After 00:00 UTC 14 July 2016 the MCS dissipated over the Vladimir and Nizhny Novgorod regions.

\subsection{Cb electrification model description}

The model describes charge generation and the separation processes in convective clouds (Gardiner et al., 1985; MacGorman et al., 2001; Mansel et al., 2005; Ziegler et al., 1991). The charges are moving hydrometeors (graupels, ice and snow crystals, cloud, and rain droplets). The input for 


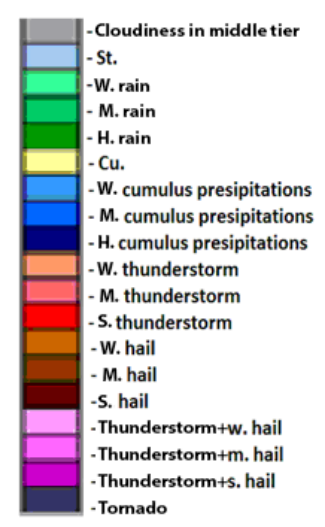

(c)

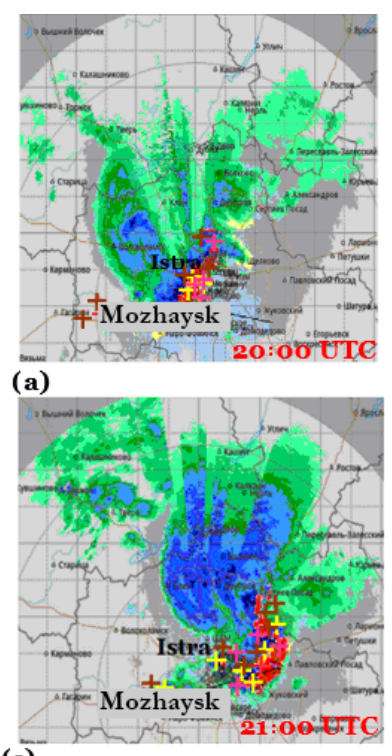

(c)

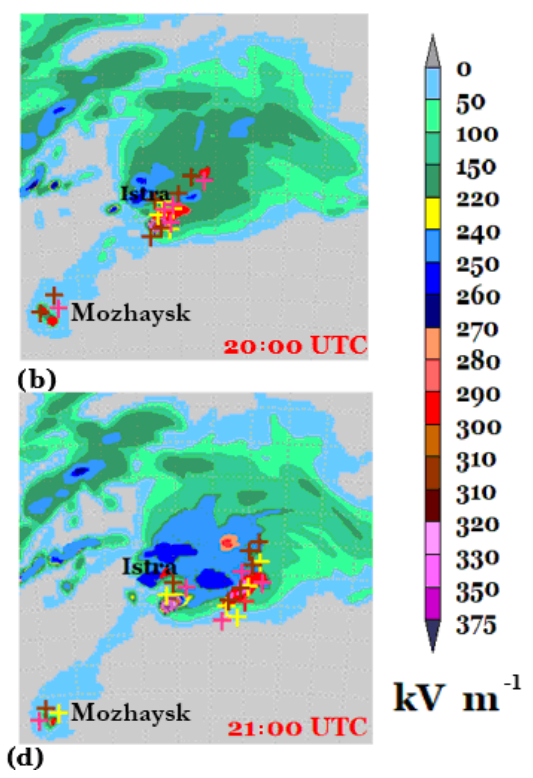

(d)

Figure 1. Passage of MCCs according to Doppler weather radar maps (a, c) and simulated electric field intensity $\left(\mathrm{kV} \mathrm{m}^{-1}\right)(\mathbf{b}, \mathbf{d})$. Moscow region, 20:00 and 21:00 UTC, 13 July 2016.

the $\mathrm{Cb}$ model are constants and the meteorological data (air temperature, wind speed, fractions of liquid and solid cloud particles). The main unit of charge generation includes equations of non-inductive and inductive schemes. Non-inductive charging occurs due to collision and rebound among the graupels, the snow and the ice crystals in the presence of supercooled water. Eq. (1) (Mansel et al., 2005) is used for calculation:

$$
\begin{aligned}
S= & \int_{0}^{\infty} \int_{0}^{\infty} \frac{\pi}{4} \delta q_{1,2}\left(1-E_{1,2}\right)\left|V_{1}-V_{2}\right| \times\left(D_{1}+D_{2}\right)^{2} \\
& n_{1}\left(D_{1}\right) n_{2}\left(D_{2}\right) d D_{1} d D_{2},
\end{aligned}
$$

where $S$ is the non-inductive charge generation among the interacting solid hydrometeors, $\mathrm{C} \mathrm{m}^{-3} \mathrm{~s} ; \delta q_{1,2}$ is the charge produced in one collision, $\mathrm{Cl} ; E_{1,2}$ is the coefficient of coagulation or collision of hydrometeors; $V_{1,2}$ is the terminal velocity of cloud particles, $\mathrm{m} \mathrm{s}^{-1}$; and $D$ is the diameter of hydrometeors, $\mathrm{m}$.

Inductive charging is caused by hydrometeors polarized with the atmospheric electric field. Equation (2) of the inductive charging implies the interaction of graupels and cloud droplets (Zeigler et al., 1991):

$$
\begin{aligned}
S & =\left(\frac{\pi}{4}\right) E_{1,2} E_{r} D_{1}^{2} V_{1} n_{2} \alpha \cdot\left[\left(\frac{\pi^{3}}{2}\right) D_{1}^{2} \varepsilon E_{z} \cos \theta\right. \\
& \left.-\left(\frac{\pi^{2}}{6}\right) \delta q_{g} \frac{D_{2}^{2}}{D_{1}^{2}}\right],
\end{aligned}
$$

where $S$ is inductive charge generation between the interacting graupels and the cloud droplets, $\mathrm{C} \mathrm{m}^{-3} \mathrm{~s} ; E_{r}=0,1$ is probability of collision among the cloud droplets; $\alpha=0.022$ is the proportion of the cloud droplets colliding tangentially; $n_{2}$ is the concentration of cloud particles; $\varepsilon$ is air permittivity; $\cos \theta=0.84$ is the cosine of angle between the cloud droplets and the graupels; and $E_{z}$ is the vertical component of the external electric field, $\mathrm{kV} \mathrm{m}^{-1}$.

The resulting charge is calculated as the sum of noninductive and inductive charges (Dovgaluik et al.,2013). Equation (3) is used for the calculation:

$S_{\text {tot }}=S_{\text {nonind }(\mathrm{g}, \mathrm{s})}+S_{\text {nonind }(\mathrm{g}, \mathrm{i})}+S_{\text {ind(g, } \mathrm{c})}$,

where $S_{\text {tot }}$ is the resulting charge, $\mathrm{Cm}^{-3} \mathrm{~s} ; S_{\text {nonind(g,s) }}$ is non-inductive charge generation between the graupels and the snow crystals, $\mathrm{C} \mathrm{m}^{-3} \mathrm{~s} ; S_{\text {nonind(g,i) }}$ is non-inductive charge generation between the graupels and the ice crystals, $\mathrm{C} \mathrm{m}^{-3} \mathrm{~s}$; and $S_{\text {ind(g,c) }}$ is inductive charge generation between the graupels and the cloud droplets, $\mathrm{C} \mathrm{m}^{-3} \mathrm{~s}$.

Pairwise interaction among other hydrometeors is not considered due to the small size of the charge generated as a result of their collision (Jennings, 1975). The charge per one collision between particles $\delta q_{1,2}$ is calculated using the equation from (Mansel et al., 2005; Ziegler et al., 1991). The terminal speed of the ice crystals, the snow particles and the graupels is obtained using formulas from Lyn et al. (1983). The transport equation of the volume charge, the electric potential and the electric field intensity are taken from Mansel et al. (2005) and Ziegler et al. (1991).

\subsection{WRF-ARW v.3.7.1 configuration}

The meteorological fields are predicted by WRF-ARW v.3.7.1. The system of nested domains with a decreasing resolution of 18,6 and $2 \mathrm{~km}$ is applied. The experiments were 
carried out for the domain of $896 \times 472$ points with a $2 \mathrm{~km}$ spatial resolution and $20 \mathrm{~km}$ height. Global Forecast System $0.5^{\circ}$ data are used as input for WRF-ARW. The forecast starts from 00:00 to 00:00 UTC 13 July 2016. The time intervals for issuing forecasts are $15 \mathrm{~min}$. The parameterizations used include microphysical processes - Thompson (Thompson et al., 2004); longwave and shortwave radiation - RRTMG (Wang et al., 2014); surface and boundary layers - BouLac (Bougeault and Lacarrere, 1987); soil processes Noah (Ek et al., 2003); and convection - Grell (Grell, 1993).

\section{Simulation results and conclusions}

Figure 1 shows the weather events $(\mathrm{a}, \mathrm{c})$ according to the Doppler weather radar and the simulated electric field intensity $\left(\mathrm{kV} \mathrm{m}^{-1}\right)(\mathrm{b}, \mathrm{d})$. The "+" symbol refers to an observed lightning strike (yellow - obtained from WWLLN database, red and brown ones - from the local Russian lightning detection network's High-Mountain Geophysical Institute (HMGI) and Main Geophysical Observatory (MGO) respectively) (Lay, 2008; Adzhiev et al., 2013; Snegurov and Snegurov, 2012). A total of 524 lightning strikes (at 20:0000:00 UTC) and 512 strikes (at 21:00-00:00 UTC) were observed over central Russia. The simulated electric field intensity (Fig. 1b, d) and the observed weather events associated with convection according to the Doppler weather radar (Fig. 1a, c) are presented. The Doppler weather radar maps are provided by Roshydromet (http://meteorad.ru/dmrl_map, last access: 21 August 2018). The shaded areas with weather events are obtained from the values of radar reflectivity using the methods of Roshydromet. In areas with thunderstorms (Fig. 1b, d) the values of simulated electric field intensity exceeded $260 \mathrm{kV} \mathrm{m}^{-1}$. At 20:00-00:00 UTC the area of thunderstorm activity over Mozhaysk is predicted correctly. Over Istra it shifted. At 21:00-00:00 UTC the zones of thunderstorm activity over the northeast and the east of the Moscow region were predicted correctly. To make the quantitative estimation of thunderstorm prediction with the critical value of $260 \mathrm{kV} \mathrm{m}^{-1}$ for the lightning initiation we obtained the forecast scores (probability of detection and false alarm ratio). Calculation of three-dimensional values of electric field intensity over a certain point with observed lightning strikes was carried out. If the value exceeds $260 \mathrm{kV} \mathrm{m}^{-1}$ we consider the predicted thunderstorm to have started at this point. The probability of detection is $95 \%$ (at 20:00-00:00 UTC) and $83 \%$ (at 21:00-00:00 UTC). False alarms are $2 \%$ (at 20:0000:00 UTC) and 7\% (at 21:00-00:00 UTC). The obtained scores show that the proposed approach to explicit modelling of the electric field is applicable to the short-term forecasting of intense convection and storm passage tracking. Obtaining varying values of the electric field could help to identify the diversity of hazardous weather phenomena associated with convection. The electric field intensity threshold with a value of $260 \mathrm{kV} \mathrm{m}^{-1}$ established for the lightning initiation shows a good balance between probability of detection and false alarm ratio estimates.

Data availability. The Doppler weather radar data are not public. They are available for researchers of Roshydromet only. Please contact the first author if the data are required.

Author contributions. IMG performed numerical experiments, statistical estimations, and analysis of the results and wrote the paper. MMK carried out numerical experiments and analysis of the results. KGR helped in the formulation of the task, analysis of the results, and writing of the paper.

Competing interests. The authors declare that they have no conflict of interest.

Special issue statement. This article is part of the special issue "17th EMS Annual Meeting: European Conference for Applied Meteorology and Climatology 2017". It is a result of the EMS Annual Meeting: European Conference for Applied Meteorology and Climatology 2017, Dublin, Ireland, 4-8 September 2017.

Acknowledgements. This work was supported by the RFBR (Russian Foundation for Basic Research) under grants mol_a 18-35-00044, A 16-05-00822 and A 16-05-00704. It was also supported by EMS through YSTA.

Edited by: Victoria Sinclair

Reviewed by: two anonymous referees

\section{References}

Adzhiev, A. K., Stasenko, V. N., and Tapsakhanov, V. O.: Lightning detection system in the North Caucasus, Russ. Meteorol. Hydro., 1, 5-11, 2013.

Bougeault, P. and Lacarrere, P: Bougeault P. Parameterization of Orography-Induced Turbulence in a Mesobeta-Scale Model, Mon. Weather Rev., 117, 1872-1890, 1987.

Dovgaluik , Y. A., Veremey, N. E., and Sinkevich, A. A.: Application of the one-and-a-half-dimensional model for solving fundamental and applied problems of cloud microphysics, 1, 220, 2013.

Ek, M. B., Mitchell, K. E., Lin, Y., Rogers, E., Grunmann, P., Koren, V., Gayno, G., and Tarpley, J. D.: Implementation of Noah land surface model advances in the National Centers for Environmental Prediction operational mesoscale Eta model, J. Geophys. Res., 108, 8851-8866, 2003.

Gardiner, B., Lamb, D., Pitter, R. L., Hallett, J., and Saunders, C. P. R.: Measurements of initial potential gradient and particle charges in a Montana summer thunderstorm, J. Geophys. Res., 90, 6079-6086, https://doi.org/10.1029/JD090iD04p06079, 1985. 
Grell, G. A.: Prognostic Evaluation of Assumptions Used by Cumulus Parameterizations, Mon. Weather Rev., 121, 764-787, 1993.

Lay, E. H.: Investigating lightning-to-ionosphere energy coupling based on VLF lightning propagation characterization, $\mathrm{PhD}$ thesis, University of Washington, Seattle, Washington State, USA, 1-142, 2008.

MacGorman, D. R., Straka, J. M., and Ziegler, C. L.: A lightning parameterization for numerical cloud models, J. Appl. Meteorol., 40, 459-478, 2001.

Mansel, E. R., MacGorman, D. R., Ziegler, C. L., and Straka, J.: Charge structure and light-ning sensitivity in a simulated multicell thunderstorm, J. Geophys. Res., 110, 12-20, https://doi.org/10.1029/2004JD005287, 2005.
Snegurov, A. V. and Snegurov, V. S.: Experimental lightning location system, Proceedings of MGO, 567, 188-200, 2012.

Thompson, G., Rasmussen, R. M., and Manning, K.: Explicit forecasts of winter precipitation using an improved bulk microphysics scheme. Part I: Description and sensitivity analysis, Mon. Weather Rev., 132, 519-542, 2004.

Wang, W., Bruyère, C., Duda, M., Dudhia, J., Gill, D., Lin, H.-C., Michalakes, J., Rizvi, S., and Zhang, X.: Weather Research and Forecasting. ARW. Version 3 Modelling Systems User's Guide, 7, 1-384, 2014.

Ziegler, C., MacGorman, J. D., and Ray, P.: A model evaluation of noninductive graupel-ice charging in the early electrization of a mountain thunderstorm, J. Geophys. Res., 96, 12833-12855, 1991. 